\title{
Influence of different Saccharomyces cerevisiae strains on the oxygen concentration in the rumen fluid
}

\author{
J. Kutasi ${ }^{1,3}$, V. Jurkovich ${ }^{2}$, E. Brydl², L. Könyves ${ }^{2}$, \\ A.E. Tirián ${ }^{2}$ and Á. Bata ${ }^{1}$ \\ ${ }^{1}$ Dr. Bata Canadian-Hungarian Biotechnological R\&D Ltd. \\ Pesti úti major, H-2364 Ócsa, Hungary \\ ${ }^{2}$ Szent István University, Faculty of Veterinary Science, Department of Animal Hygiene, \\ Herd Health and Veterinary Ethology \\ István utca 2., H-1078 Budapest, Hungary
}

\begin{abstract}
The oxygen utilization properties of different commercially available yeast (Saccharomyces cerevisiae) products were tested in vitro in artificially created ruminal environment. It has been established that different yeast strains have different oxygen consuming capacity and this characteristic changes in case of prior anaerobic incubation. It was shown that Live-Sacc ${ }^{\circledR}$ (NCAIM deposited strain) is a powerful fermentative, it quickly extracts $\mathrm{O}_{2}$ from the rumen fluid and the anaerobic conditions have no effect on its oxygen consuming capacity.
\end{abstract}

KEY WORDS: Saccharomyces cerevisiae, rumen fluid, oxygen

\section{INTRODUCTION}

The interest in the use of direct-fed microbials (DFM) as feed additives for high yielding dairy cows has increased in recent years. Viable Saccharomyces cerevisiae is one of the most widely used DFM in feeding of ruminants. Yeast products have been shown to modify rumen fermentation (Wiedmeyer et al., 1987), to stimulate the growth of rumen bacteria (Newbold et al., 1995) and to increase the initial rate of forage digestion in the rumen (Williams et al., 1991) resulting in increased concentration of VFAs in the rumen fluid (Brydl et al., 1995). The increased bacterial growth may be due to the oxygen utilization of

The authors thank Mikolt Bakony for language supervision

${ }^{3}$ Corresponding author: e-mail: kutasi@drbata.com 
the yeast cells and the inconsistency arises from the varying metabolic activity of different yeast strains (Newbold et al., 1996).

The aim of our study was to measure the oxygen consumption of Live-Sacc ${ }^{\circledR}$ and compare it with two commercially available products.

\section{MATERIAL AND METHODS}

The following three commercially available Saccharomyces cerevisiae strains were tested: Live-Sacc ${ }^{\circledR}$ (LS, produced by Dr. Bata Ltd, strain is deposited in the NCAIM, Budapest, Hungary), the NCYC Sc 47 strain (B) and the BCCM/MUCL 39885 strain (C). The strains were maintained in continuous culture in shaker flasks and inlet fermentors on YPD (yeast extract, pepton and glucose) medium. For the determination of the total number of microbes the streak-plate method (YPD agar) was used. The cell count ranged between 1.5$2.2 \times 10^{10} \mathrm{CFU} / \mathrm{g}$. To determine the effect of different yeast preparations on $\mathrm{O}_{2}$ removal in vitro incubations were carried out with rumen fluid withdrawn from rumen cannulated sheep. The rumen fluid was maintained in Braun DCU Tower automatised artificial rumen fermentor on $\mathrm{pH}$ value 6.8 and $1 \mathrm{mg} / \mathrm{l}$ oxygen concentration. Yeast products were added to the rumen fluid in 1.0, 0.3 and $0.1 \mathrm{~g}$ (dry matter $) / 1$ concentration. Afterwards the oxygen concentration of the rumen fluid was measured in every minute by means of Ingold oxygen electrode. In an other study the yeast preparations were mixed in LBPM rumen buffer with starch supplement and the samples were incubated in anaerobic conditions (95\% carbon dioxide and 5\% nitrogene) for $12 \mathrm{~h}$. After incubation the tests were carried out the way mentioned above.

\section{RESULTS}

The oxygen concentration of the rumen fluid correlates with the yeast cell concentration (Figure 1). Oxygen was consumed faster (within $15 \mathrm{~min}$ ) in case of $1 \mathrm{~g} / 1$ yeast (LS) concentration, while it was about $200 \mathrm{~min}$ when $0.1 \mathrm{~g} / 1 \mathrm{LS}$ added. On terms of $0.3 \mathrm{~g} / \mathrm{l} \mathrm{LS}$ the oxygen concentration of the rumen fluid decreased to zero within $50 \mathrm{~min}$. Henceforth we compared the oxygen removal capacity of the different yeast strains at $0.3 \mathrm{~g} / 1$ concentration. Strain B removed the oxygen from the rumen fluid similarly to LS within $60 \mathrm{~min}$. Strain C needed almost three hours to reduce the oxygen concentration to zero (Figure 2). The oxygen utilization ability of the different yeast strains was also measured following previous anaerobic incubation. Findings showed significant differences. LS strain removed the oxygen from the rumen fluid within $20 \mathrm{~min}$. Strain B eliminated the oxygen within 60 min but strain $\mathrm{C}$ showed no metabolic activity after anaerobic incubation (data are not shown). 


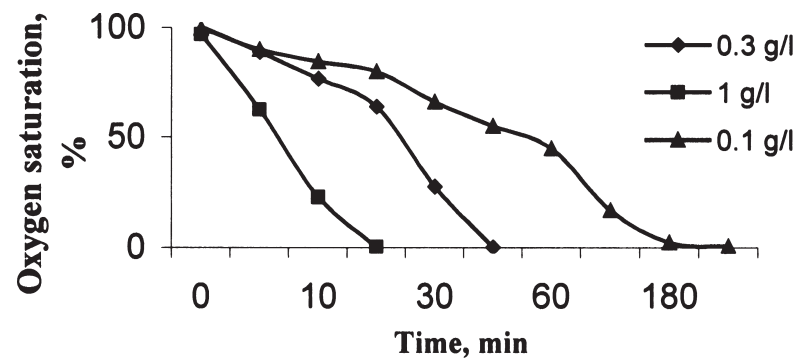

Figure 1. The oxygen removal capacity of Live-Sacc ${ }^{\circledR}$ in different doses

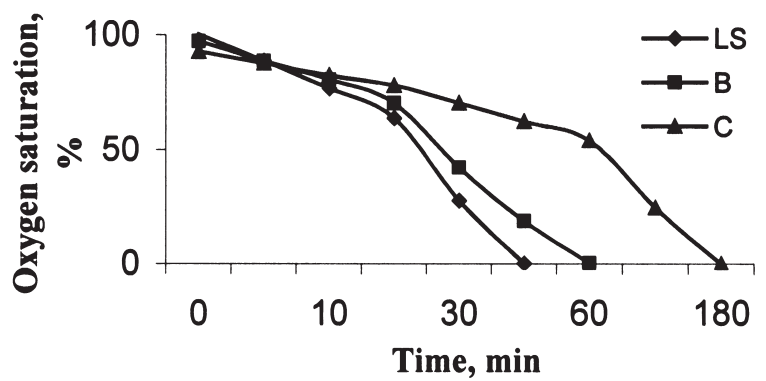

Figure 2. The oxygen removal capacity of different yeast strains in $0.3 \mathrm{~g} / \mathrm{L}$ dose

\section{DISCUSSION}

S. cerevisiae does not grow in rumen fluid (Arambel and Tung, 1987) but retains its metabolic activity (Ingledew and Jones, 1982) and viability (El Hassan, 1993). Several metabolic characteristics of the yeast could affect ruminal fermentation. One of these factors is the oxygen consumption. Rumen content is anaerobic but traces of dissolved oxygen can be detected during the daily feeding cycle (Scott et al., 1983). Oxygen is toxic to anaerobic bacteria and inhibits the growth of rumen bacteria and the adhesion of cellulolytic bacteria to cellulose (Roger et al., 1990). In our experiment we found that the different yeast strains seem to have different metabolic activity indicated by the different oxygen consumption ability. This finding was confirmed by Newbold et al. (1996). Our product (Live-Sacc ${ }^{\circledR}$ ) worked effectively at both 1.0 and $0.3 \mathrm{~g} / \mathrm{L}$ concentration in the rumen fluid and eliminated $\mathrm{O}_{2}$ within 15 and $50 \mathrm{~min}$. Differences exist between strains of $S$. cerevisiae in their ability to modify the rumen bacterial population (Newbold et al., 1995). The ability of different yeast preparations to stimulate the viable count of bacteria in the sheep rumen appears to correspond with their ability to eliminate $\mathrm{O}_{2}$ from the rumen fluid. Studies suggest that $\mathrm{O}_{2}$ consumption is required for the activity of yeast cells (Newbold et al., 1996). Cellulolytic bacteria appear to be more sensitive to dissolved oxygen than the 
overall population and therefore more responsive to the protection provided by yeast (Newbold et al., 1996). Visser et al. (1990) showed that $S$. cerevisiae as an intense fermentative can readily adapt to anaerobic conditions. In our second study we established that the yeast strains adapt differently to the anaerobic conditions. Our product showed unchanged metabolic activity after $12 \mathrm{~h}$ anaerobic incubation and removed $\mathrm{O}_{2}$ from the rumen fluid within $20 \mathrm{~min}$. A similar process could be observed in case of strain B though its oxygen removing capacity was lower than that of LS. Strain C could not extract oxygen from the rumen fluid after anaerobic incubation.

We concluded that low oxygen concentration in the rumen fluid can be reached by using $S$. cerevisiae strains selected for fermentation in anaerobic environment. Live-Sacc $^{\circledR}$ applicated in $0.3 \mathrm{~g} / \mathrm{L}\left(4.5-6.6 \times 10^{9} \mathrm{CFU} / \mathrm{L}\right)$ concentration seems suitable to improve ruminal fermentation by decreasing the oxygen concentration in the rumen fluid.

\section{REFERENCES}

Arambel M.J, Tung R.S., 1987. Evaluation of Saccharomyces cerevisiae growth in the rumen ecosystem. Proceedings of $19^{\text {th }}$ Biennial Conference on Rumen Function, Chicago, p. 29

Brydl E., Bata Á., Rafai P., Lasztity R., Vajdovich K., Nagy G., 1995. Effect of viable Saccharomyces cerevisiae on the rumial fermentation, acid-base metabolism and milk production of dairy cows (in Hungarian). Magyar Állatorvosok Lapja 50, 543

El Hassan S.M., Wallace R.J., Newbold C.J., Chen B.X., Edwards J.E., Topps J.H., 1992. Effects of yeast culture on rumen fermentation and live-weight gain in bulls fed isonitrogenous diets of barley/urea or barley/soya. Anim. Prod. 54, 504 (Abstr. 211)

Ingledew W.M., Jones G.A., 1982. The fate of live brewers yeast slurry in bovine rumen fluid. J. Inst. Brew. 88, 18-20

Newbold C.J., Wallace R.J., Chen X.B., McIntosh F.M., 1995. Different strains of Saccharomyces cerevisiae differ in their effects on ruminal bacterial numbers in vitro and in sheep. J. Anim. Sci. 73, 1811-1818

Newbold C.J., Wallace R.J., McIntosh F.M., 1996. Mode of action of the yeast Saccharomyces cerevisiae as feed additive for ruminants. Brit. J. Nutr. 76, 249-261

Roger V., Fonty G., Komisarczuk-Bony S., Gouet P., 1990. Effects of physicochemical factors on the adhesion to cellulose Avicel of the rumen bacteria Ruminococcus flavefaciens and Fibrobacter succinogenes ssp. succinogenes. Appl. Environ. Microbiol. 56, 3081-3087

Scott R.I., Yarlett N., Hillman K., Williams T.N., Williams A.G., Lloyd D., 1983. The presence of oxygen in rumen liquor and its effect on methanogenesis. J. Appl. Bacteriol. 55, 143-149

Swartz D.L., Muller D., Rogers G.W., Varga G.A., 1994. Effect of yeast cultures on performance of lactating dairy cows: a field study. J. Dairy Sci. 77, 3073-3080

Visser W., Schieffers A., Batenburg-Van der Vegte W., Van Dijken J.P., 1990. Oxygen requirements of yeasts. Appl. Environ. Microbiol. 56, 3785-3792

Wiedmeyer R.D., Arambel M.J., Walters J.L., 1987. Effect of yeast culture and Aspergillus oryzae fermentation extract on ruminal characteristics and nutrient digestibility. J. Dairy Sci. 70, 20632068

Williams P.E.V., Tait C.A.G., Innes G.M., Newbold C.J., 1991. Effects of the inclusion of yeast culture (Saccharomyces cerevisiae plus growth medium) in the diet of dairy cows on milk yield and forage degradation and fermentation patterns in the rumen of sheep and steers. J. Anim. Sci. 69, 3016-3026 